\title{
A Proposal of Case Based Reasoning System for the Appropriate Selection of Components Using CBD
}

\author{
Abrar Omar Alkhamisi, M. Rizwan Jameel Qureshi \\ Faculty of Computing and Information Technology, King Abdulaziz University, Jeddah, Saudi Arabia \\ E-mil:abrar200828@yahoo.com,anriz@hotmal.com
}

\begin{abstract}
Software engineering starts to be less linked to the development, but at the same time it tends to rely on using the component-based software. The community interested in software engineering has proposed what is called software reuse and offered some ways for component-based software develop ment. The basic difficulty encountered when designing component-based systems is the process of searching for and selecting the appropriate set of the current software components. Selecting a component is considered a hard task in the Component Based Software Engineering (referred to as CBSE), particularly with the augmentation of the number of the component development. Hence, it is hard to select component for CBSE. Different ways and approaches were suggested to solve the problem related to software component selection. Validation of the proposed solution in this paper through collecting a sample of people who answer an electronic survey that composed of 15 questions. An electronic survey target distributed to specialists in software engineering through social sites such as twitter and Facebook also by email them. The result of the validation of the proposed solution proved using a new improvement CBR system to do select the suitable component .
\end{abstract}

Index Terms - CBSE: Component Based Software Engineering, CBR: Case Based Reasoning System, OTSO: Off-The-Self Software

\section{Introduction}

Software engineering came to be less connected with the development; however, it tended to utilize the component-based software. The community concerned with software engineering has suggested what is called software reuse that is the process of creating software systems from predefined software components and submitted some procedures for component-based software development. Hence, the CBD is interested in developing the software from the pre manufactured components and the possibility of re-utilizing and keeping up those components. Those components are referred to as a software component.
Since the software reuse began to have a noticeable effect, CBD has contributed greatly in decreasing the time needed to achieve development, augmenting flexibility, and raised the trustworthiness of the component-based systems. Of course, designing, carrying out, experimenting, fixing and documenting a component take more time than purchasing a component. Also, it is obvious that the self-contained components which present a group of specific functions in a system can be substituted without difficulty or problems. Furthermore, the components utilized in other systems are considered more mature than the new advancements.

The basic difficulties faced when designing the component-based systems are represented in choosing and finding out a proper group of accessible software components. This obstacle is referred to as the component choice problem whereas nowadays the task of finding a group of components to perform the needed functions came to be a hard task. After defining the potential candidate components, a subsection of all candidates has to be chosen in such a way that meets the developer's goals. Then the following obstacle is represented in choosing a subgroup where all components are consistent with each other. It is worth noting that it is very hard to carry out the task of choosing and searching for proper components manually, particularly for larger systems.

In spite of the fact that there is no commonly approved way for choosing the component, there are no specific rules and procedures for performing the component choice task. Therefore, every project carries out this task on his own way. There are numerous means that can handle the component selection problem. Hence, the improve case-based reasoning system approach is tackled as a solution for this problem.

The remainder of this paper is organized as follows: Section 2 describes some brief literature review. Section 3 the authors have described the statement of the problem. Section 4 solution towards that problem is given. Section 5 the solution is validated by the means of a survey. Conclusion and future work are given in the final section. 


\section{Related Work}

The Component-Based Software Engineering is responsible for selecting, designing, and putting such components together. Since this method becomes more common and the number of the commercially accessible software components increases, the selection of a set of components that meet the requirements with low costs becomes very difficult. Hence, this problem makes it important to be concerned with designing effective greedy and genetic algorithms [1] in order to computerize the component selection for software developing organization approaches utilized to handle this problem. On the other hand, other approaches handle this problem through utilizing evolutionary algorithms ${ }^{[2]}$.

The component selection is considered a critical problem in CBSE that is interested in gathering the preexisting software components; the matter that results in creating a software system that is compatible with the client-specific needs and demands. There are two types of the evolutionary approaches utilized ${ }^{[3]}$. The first one evolutionary depends on components (EAc) while the second one evolutionary depends on requirements (EAr).

The difficulty of selecting a component from a group of components is not considered a unique one. Generally, there are various substitute components which might be selected whereas every one of them meets specific needs and requirements. It is significant to select the most efficient substitutes; hence, it is necessary to assess the components. Therefore, these approaches $[4,5]$ achieve formulate the problem as multiobjective whereas the various metric values have been put into consideration and the principles of evolutionary algorith $m$ have been utilized when handling this problem.

Also, there is the difficulty of selecting the most proper components that meet the demands and needs without incurring high costs. The evolutionary algorithms ${ }^{[6]}$ are utilized here to hand this difficulty.

The process of re-utilizing the available components when designing a system saves time, but at the same time selecting the proper components that can meet the system requirements is a difficult task for a number of reasons. First of all, the specifics of the current components should embrace all data and information needed by the designers in order to take the proper decisions related to the selection of the most proper components. Also, the system designer faces difficulty when selecting between various components having similar functionality and varying in their quality and performance level. In this research ${ }^{[7]}$, the component selection problem can be overcome through utilizing the simulated annealing method.

The component selection is considered a hard task in CBSE. The first matter ${ }^{[8]}$ considered when selecting a component is the cost which calculated basis the component quality and specification. Selecting the component according to this approach is considered a part of OTSO method that was designed primarily for this purpose.

Selecting a component from a set of components is a big problem [9]. To face this problem, the system require ments should be reduced in order to dimin ish the number of the components that will be selected from. Then, a greedy approach should be followed when selecting the component whereas this approach relies on the components characteristics and features.

Carrying out ${ }^{[10]}$ the component selection task efficiently contributes greatly to the success of the system. In order to resolve the component selection problem, a comparison is drawn between the case based reasoning system approach and the conventional component selection methods.

Table 1: Comparison of Related Work

\begin{tabular}{|c|c|}
\hline Paper Title with Reference Number & Problems Found \\
\hline $\begin{array}{l}\text { Approximation Algorithms for Software } \\
\text { Component Selection Problem }{ }^{[1]} \text {. }\end{array}$ & $\begin{array}{l}\text { - The experiments minimizing the number of components used. } \\
\text { - The experiment's environment uses ActiveX controls as the set of components. } \\
\text { - Each ActiveX control has a set of characteristics. In this study, Each ActiveX control } \\
\text { characteristic is assumed to be a requirement which can be satisfied with it. } \\
\text { - Dataset using in experiments a set of } 60 \text { components downloaded from the Internet. } \\
\text { - Algorithms use for this problem specific cases in which utility of a component regarding a } \\
\text { requirement discrete zero or one values assumed here. } \\
\text { - In the experiment not including non-functional requirements in the set of requirements. }\end{array}$ \\
\hline $\begin{array}{l}\text { Evolutionary Algorithms for the } \\
\text { Component Selection Problem }{ }^{[2]} \text {. }\end{array}$ & $\begin{array}{l}\text { - In this experiment discussed not considered the dependencies bet ween the requirements that } \\
\text { have to be satisfied by the final system. } \\
\text { - In this experiment better results are obtained with smaller number requirements. }\end{array}$ \\
\hline $\begin{array}{l}\text { Two Evolutionary Multiobjective } \\
\text { Approaches for the Component Selection } \\
\text { Problem }{ }^{[3]} \text {. }\end{array}$ & $\begin{array}{l}\text { - Limitation number of requirements and available components that used in the experiment. } \\
\text { - Quality at tributes for non-functional requirements do not consider in this experiment. }\end{array}$ \\
\hline $\begin{array}{l}\text { A Metrics-based Evolutionary Approach } \\
\text { for the Component Selection Problem }{ }^{[4]} \text {. }\end{array}$ & $\begin{array}{l}\text { - Limitation in this study metrics that use for select component three attributes: cost, } \\
\text { reusability and functionality. } \\
\text { - In this experiment limitation number of components and requirements that used in the study. }\end{array}$ \\
\hline
\end{tabular}




\begin{tabular}{|c|c|}
\hline Paper Title with Reference Number & Problems Found \\
\hline $\begin{array}{l}\text { Pareto dominance - based approach for the } \\
\text { Component Selection Problem }{ }^{[5]} \text {. }\end{array}$ & $\begin{array}{l}\text { - Limitation number requirements and components that used. } \\
\text { - Limitation in this experiment does not mention non-functional requirements when select } \\
\text { component. }\end{array}$ \\
\hline $\begin{array}{l}\text { An evolutionary multiobjective approach } \\
\text { for the Component Selection Problem }{ }^{[6]} \text {. }\end{array}$ & $\begin{array}{l}\text { - In this experiment used dependencies bet ween the requirements of the system. } \\
\text { - In this experiment limitation number of components and requirements. }\end{array}$ \\
\hline $\begin{array}{l}\text { An Integrated Component Selection } \\
\text { Framework for System-Level Design }{ }^{[7]} \text {. }\end{array}$ & $\begin{array}{l}\text { - In this paper limitation proposed applied the problem selecting of components for Net work- } \\
\text { on-Chip (NOC) architecture. } \\
\text { - Limitation number of requirements that used. }\end{array}$ \\
\hline $\begin{array}{l}\text { Component Selection for Component based } \\
\text { Soft ware Engineering }{ }^{[8]} \text {. }\end{array}$ & $\begin{array}{l}\text { - Limitation in OT SO method domain specific characteristics that would limit the applicability } \\
\text { of the method in other domains. } \\
\text { - Limitation in the requirement specification may not be detailed enough for evaluating OTS } \\
\text { software alternatives. } \\
\text { - Case study in this experiment relatively small, the evaluation processes and the resulting } \\
\text { criteria. }\end{array}$ \\
\hline $\begin{array}{l}\text { Component selection strategies based on } \\
\text { system requirements' dependencies on } \\
\text { component at tributes }^{[9]} \text {. }\end{array}$ & $\begin{array}{l}\text { - Limitation in paper components satisfying the system requirements cannot be found within } \\
\text { the existing components and new components need to be developed. } \\
\text { - This approach depended only the given satisfied system requirements. }\end{array}$ \\
\hline $\begin{array}{l}\text { A Study on Software Component Selection } \\
\text { Methods }{ }^{[10] .}\end{array}$ & $\begin{array}{l}\text { - The drawback of this approach is that firstly they need to have a case base and database of } \\
\text { components to use approach that not availability many cases in the beginning. }\end{array}$ \\
\hline
\end{tabular}

\section{Problem Statement}

Selecting a proper component became a hard task due to the increasing number of the reusable components. Users can easily examine tens of the existing components in order to determine the most suitable ones. However, they cannot examine hundreds or thousands of components in order to accurately select the components they require.

This question is taken up in this paper to add the problem reviewers ${ }^{[1-10]}$ : 'How to identify appropriate components to satisfy users' requirements?' is considered one of the main problems connected with the component reuse. The emersion of various component architecture criteria increases the seriousness of this problem. The next section submits the proposed solution to this problem.

\section{The Proposed Solution for Component Selection Problem}

Some approaches have been provided in order to solve the component selection problem. In this paper propose an approach that can handle this problem through using the improve Case Based Reasoning System in order to contribute in supporting the decision making process. The CBR system ${ }^{[10]}$ sets down a group of functionalities and utilizes similar components to perform those functionalities. Also, it assumes that the user requirements are considered as cases. With the passage of time, the casebase is regarded as a database for components which might be considered as a general knowledge for resolving the problem ${ }^{[10]}$. Sometimes, cases needed to fully accomplish problem functionalities may be unavailable. In such cases, the database can assist greatly in handling the problem functionalities ${ }^{[10]}$. In this section, going to give briefly introduce the tasks of improving the CBR system.

Case-based reasoning originates from the field of artificial intelligence that is utilized for reasoning and learning ${ }^{[11]}$. The CBR system utilizes previous experience in order to solve problems ${ }^{[11]}$. When the CBR is utilized, all the records or elements of the preceding problem will be stored in the database to be easily used and accessed when trying to resolve similar problems ${ }^{[11]}$. In this paper, the authors add two features to improve CBR system to overcome the drawback as shown below.

- The first one is represented in providing the CBR system with a database that includes all the potential cases that may help in solving the problem. This database is very important because when the CBR system was utilized for the first time, the outcomes have been unsatisfactory due to the lack of sufficient cases that assist in selecting the most suitable component that can satisfy the requirements.

- The second one is represented in adding new task the assurance task. After selecting the proper component from the CBR system stored temporally in the database, this procedure is reiterated again automatically to ensure the selection of the same outcome of the CBR system. If the outcome is different, the improve CBR system will in his turn combine the two components to create a new one meeting the user requirements and demands.

Improve CBR system has five tasks: Retrieve, Reuse, Assurance, Revise, Retain. Improve CBR system is shown in figure 1. 


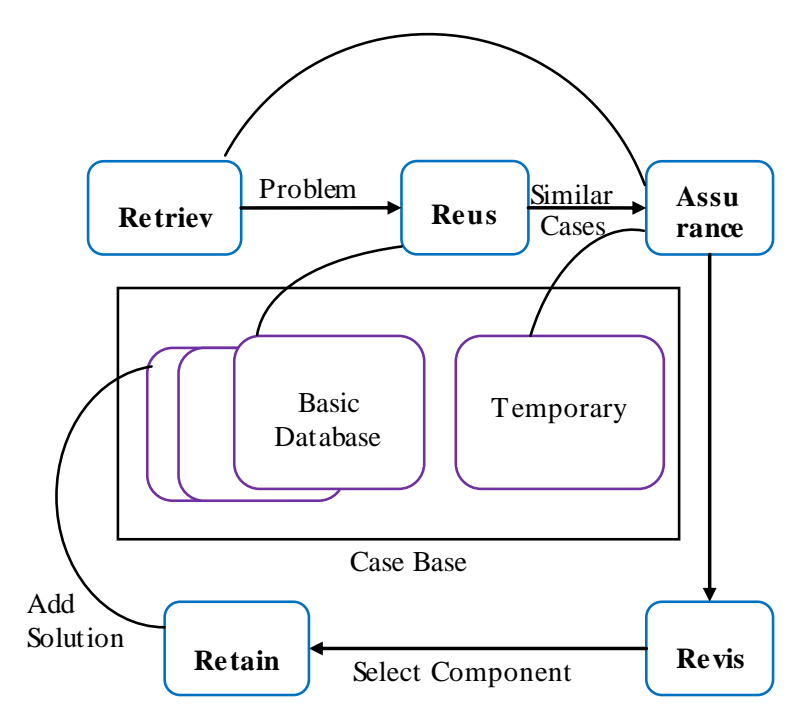

Fig. 1: The Proposed Case Based Reasoning System

- As for the retrieve task, it depends on retrieving the component from the set of components in the database ${ }^{[10]}$. Also, this task consists of a number of subtasks that are shown as follows:

1. Determination features: It is important to identify the requirements the problem description base the index of casebase ${ }^{[10]}$.

2. Searching: basis of requirements problem description is searched component similar to problem description and returned this component [10]

- As for the reuse task, it depends on one of two ways to copy or to adjust ${ }^{[10]}$. Copy means to utilize the chosen component solution. On the other hand, adjust means that the selected component solution has changed in such a way that go well with the new problem ${ }^{[10]}$.

- The assurance task follows directly the reuse task. In other words, after performing the reuse task (i.e. selecting the proper component from the CBR system stored temporally in the database), this procedure is reiterated again to ensure the selection of the same outcome of the CBR system. If the outcome is different, the improve CBR system will in his turn combine the two components to create a new one meeting the user requirements and demands. After that the revise task to evaluation solution.

- The revise task is a significant one whereas in this stage the user revises the solutions recommended by the system. Also, the revise task can be divided into two stages:

1. Assessing the solution: In this stage, the success degree of the component selected to meet the user needs and requirements is assessed ${ }^{[10]}$.
2. Correcting mistakes: In this stage, if any fault is discovered in the existing solution, it should be illustrated and corrected ${ }^{[10]}$.

- The retain task is concerned with saving the problems solved in the system database whereas they are considered a part of a new component ${ }^{[10]}$.

\section{Validation of the Proposed Solution}

Validation of the proposed solution is one of the most important points that need to any research.

In this paper the validation of the proposed solution through used an electronic survey. The purpose of using this method it's not too much time consuming and gives the respondent much of time to thin $\mathrm{k}$ and answer questions be credible. Validation of the proposed solution will be through collecting a sample of people who answer an electronic survey that composed of 15 questions. An electronic survey will be target distributed to specialists in software engineering through social sites such as twitter and Facebook also by email them. The Likert scale is the scale will be used in this research to answer questionnaire. Likert scale is given in the following Table 2.

Table 2: Likert scale

\begin{tabular}{|c|c|}
\hline 1 & Strongly Disagree \\
\hline 2 & Disagree \\
\hline 3 & Neither Agreed Nor Disagree \\
\hline 4 & Agreed \\
\hline 5 & Strongly Agreed \\
\hline
\end{tabular}

Questions divided into 3 goals were arranged according to their relevancy to defined goals this goal:

Goal 1: Management problem can be faced when selected component manual particularly with the augmentation of the number of the component development.

Goal 2: Need prefect and effective automatic to do select components especially when the large number of components available.

Goal 3: The prove used to improve the CBR system to do select the suitable component.

A statistical analysis is made on the basis of gathering data through the distribution of questionnaires The analytic form is represented through frequency tables and charts showing the exact degree of analysis. The describe the validation results on the basis of results below.

\section{Goal 1:}

Management problem can be faced when selected component manual particularly with the augmentation of the number of the component development. 


\section{Goal: 1}

Q1: Do you agree the select component is one of the major problems when using reuse component?

Results of total respondents 34 of question 1 given in Table 3 showing that $76 \%$ (where $44 \%$ strongly agreed and $32 \%$ agreed) the people were supportive to question 1 that it is agree the select component is one of the major problems when using reuse component whereas $3 \%$ of the people were not agreed. The percentage of the people who has a neutral opinion neither agreed nor disagree is $21 \%$. The conclusion of the survey of this question is that the select component is one of the major problems when using reuse component. Following is the Table 3 showing the results obtained for the question 1 .

Table 3: Result for Question 1

\begin{tabular}{|c|c|c|c|}
\hline $\begin{array}{c}\text { Likert } \\
\text { Scale }\end{array}$ & Frequency & Percent & $\begin{array}{c}\text { Cumulative } \\
\text { Percent }\end{array}$ \\
\hline 1 & 0 & $0 \%$ & $0 \%$ \\
\hline 2 & 1 & $3 \%$ & $3 \%$ \\
\hline 3 & 7 & $21 \%$ & $24 \%$ \\
\hline 4 & 11 & $32 \%$ & $56 \%$ \\
\hline 5 & 15 & $44 \%$ & $100 \%$ \\
\hline $\begin{array}{c}\text { Total } \\
\text { respondents }\end{array}$ & $\mathbf{3 4}$ & \multicolumn{2}{|c|}{$\mathbf{1 0 0 \%}$} \\
\hline
\end{tabular}

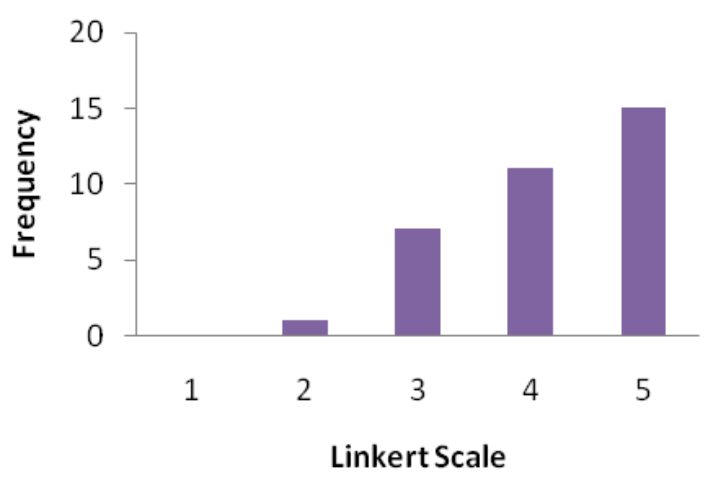

Fig. 2: Graphical Representation of Question 1

\section{Goal: 1}

Q2: Have the company any problem face when select the wrong component?

Results of total respondents 34 of question 2 given in Table 4 showing that $91 \%$ (where $35 \%$ strongly agreed and $56 \%$ agreed) the people were supportive to question 2 that it is agree the company face problem when select the wrong component. The percentage of the people who have a neutral opinion neither agreed nor disagree is $9 \%$. The conclusion of the survey of this question is that the company face problem when select the wrong component. Following is the Table 4 showing the results obtained for the question 2 .
Table 4: Result for Question 2

\begin{tabular}{|c|c|c|c|}
\hline $\begin{array}{c}\text { Likert } \\
\text { Scale }\end{array}$ & Frequency & Percent & $\begin{array}{c}\text { Cumulative } \\
\text { Percent }\end{array}$ \\
\hline 1 & 0 & $0 \%$ & $0 \%$ \\
\hline 2 & 0 & $0 \%$ & $0 \%$ \\
\hline 3 & 3 & $9 \%$ & $9 \%$ \\
\hline 4 & 19 & $56 \%$ & $65 \%$ \\
\hline 5 & 12 & $35 \%$ & $100 \%$ \\
\hline $\begin{array}{c}\text { Total } \\
\text { respondents }\end{array}$ & $\mathbf{3 4}$ & \multicolumn{2}{|c|}{$\mathbf{1 0 0 \%}$} \\
\hline
\end{tabular}

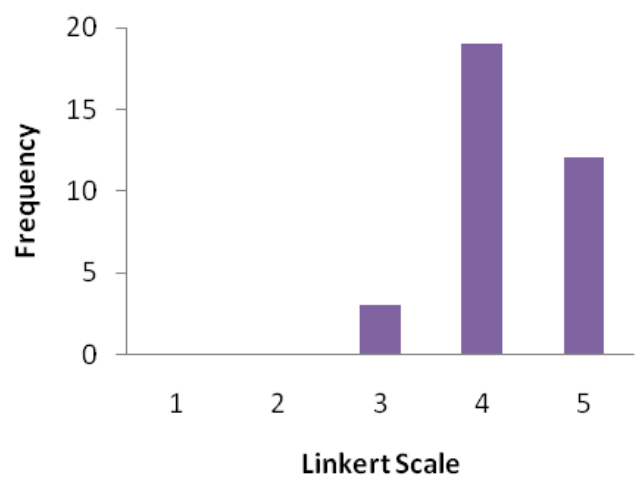

Fig. 3: Graphical Representation of Question 2

\section{Goal: 1}

Q3: How much acceptable for users to look through tens of available components to identify the most appropriate ones?

Results of total respondents 34 of question 3 given in Table 5 showing that $62 \%$ (where $21 \%$ strongly agreed and $41 \%$ agreed) the people were supportive to question 3 that it is agree the acceptable for users to look through tens of available components to identify the most appropriate ones. The percentage of the people who have a neutral opinion neither agreed nor disagree is $38 \%$. The conclusion of the survey of this question is that acceptable for users to look through tens of available components to identify the most appropriate ones. Following is the Table 5 showing the results obtained for the question 3 .

Table 5: Result for Question 3

\begin{tabular}{|c|c|c|c|}
\hline $\begin{array}{c}\text { Likert } \\
\text { Scale }\end{array}$ & Frequency & Percent & $\begin{array}{c}\text { Cumulative } \\
\text { Percent }\end{array}$ \\
\hline 1 & 0 & $0 \%$ & $0 \%$ \\
\hline 2 & 0 & $0 \%$ & $0 \%$ \\
\hline 3 & 13 & $38 \%$ & $38 \%$ \\
\hline 4 & 14 & $41 \%$ & $79 \%$ \\
\hline 5 & 7 & $21 \%$ & $100 \%$ \\
\hline $\begin{array}{c}\text { Total } \\
\text { respondents }\end{array}$ & $\mathbf{3 4}$ & \multicolumn{2}{|c|}{$\mathbf{1 0 0 \%}$} \\
\hline
\end{tabular}




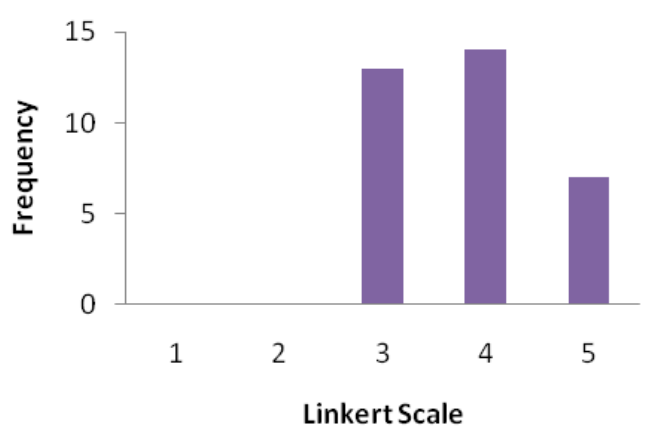

Fig. 4: Graphical Representation of Question 3

\section{Goal: 1}

Q4: How much acceptable for users to look through hundreds, or thousands of candidate components to select what they really need?

Results of total respondents 34 of question 4 given in Table 6 showing that $97 \%$ (where $88 \%$ strongly disagree and $9 \%$ disagree) the people were not supportive question 4 that it is not agree the acceptable for users to look through hundreds, or thousands of candidate components to select what they really need. The percentage of the people who has a neutral opinion neither agreed nor disagree is $3 \%$. The conclusion of the survey of this question is that not acceptable for users to look through hundreds, or thousands of candidate components to select what they really need. Following is the Table 6 showing the results obtained for the question 4.

Table 6: Result for Question 4

\begin{tabular}{|c|c|c|c|}
\hline $\begin{array}{c}\text { Likert } \\
\text { Scale }\end{array}$ & Frequency & Percent & $\begin{array}{c}\text { Cumulative } \\
\text { Percent }\end{array}$ \\
\hline 1 & 30 & $88 \%$ & $88 \%$ \\
\hline 2 & 3 & $9 \%$ & $97 \%$ \\
\hline 3 & 1 & $3 \%$ & $100 \%$ \\
\hline 4 & 0 & $0 \%$ & $100 \%$ \\
\hline 5 & 0 & $0 \%$ & $100 \%$ \\
\hline $\begin{array}{c}\text { Total } \\
\text { respondents }\end{array}$ & $\mathbf{3 4}$ & \multicolumn{2}{|c|}{$\mathbf{1 0 0 \%}$} \\
\hline
\end{tabular}

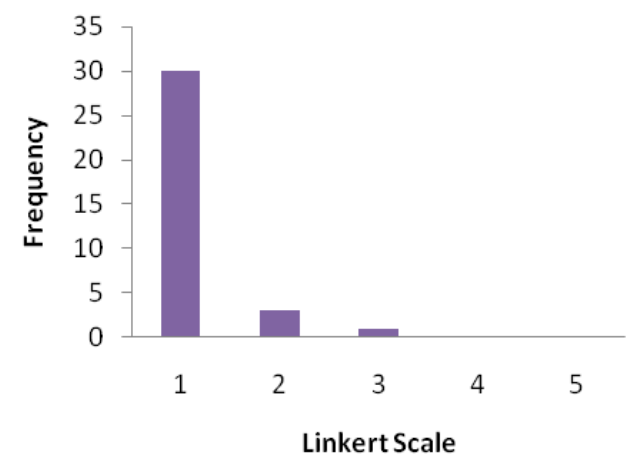

Fig. 5: Graphical Representation of Question 4
Goal: 1

Q5: How much difficult and time consuming to find a perfect component by present manual when not used automate component selection software?

Results of total respondents 34 of question 5 given in Table 7 showing that $94 \%$ (where $47 \%$ strongly agreed and $47 \%$ agreed) the people were supportive to question 5 that it is agree that difficult and time consuming to find a perfect component by present manual when not used automate component selection software. The percentage of the people who have a neutral opinion neither agreed nor disagree is $6 \%$. The conclusions of the survey of this question are that difficult and time consuming to find a perfect component by present manual when not used automate component selection software. Following is the Table 7 showing the results obtained for the question 5 .

Table 7: Result for Question 5

\begin{tabular}{|c|c|c|c|}
\hline $\begin{array}{c}\text { Likert } \\
\text { Scale }\end{array}$ & Frequency & Percent & $\begin{array}{c}\text { Cumulative } \\
\text { Percent }\end{array}$ \\
\hline 1 & 0 & $0 \%$ & $0 \%$ \\
\hline 2 & 0 & $0 \%$ & $0 \%$ \\
\hline 3 & 2 & $6 \%$ & $6 \%$ \\
\hline 4 & 16 & $47 \%$ & $53 \%$ \\
\hline 5 & 16 & $47 \%$ & $100 \%$ \\
\hline $\begin{array}{c}\text { Total } \\
\text { respondents }\end{array}$ & $\mathbf{3 4}$ & \multicolumn{2}{|c|}{$\mathbf{1 0 0 \%}$} \\
\hline
\end{tabular}

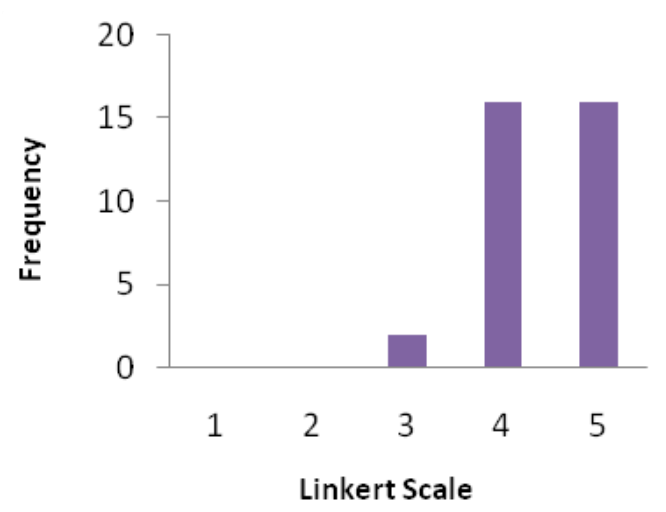

Fig. 6: Graphical Representation of Question 5

\subsection{Cumulative Survey of Goal 1}

Questions divided into 3 goals the first goal covers that management problem can be faced when selected component manual particularly with the augmentation of the number of the component development. That's show $17.64 \%$ are strongly disagreed and $2.35 \%$ are disagree 15 . $29 \%$ are neither agreed nor disagree $35.29 \%$ are agreed and $29.41 \%$ are strongly agreed. 
Table 8: Frequency Table of Cumulative Goal 1

\begin{tabular}{|c|c|c|c|c|c|}
\hline Q.No & Strongly Disagree & Disagree & Neither Agree nor Disagree & Agree & Strongly Agree \\
\hline 1 & & 1 & 7 & 11 & 15 \\
\hline 2 & & & 3 & 19 & 12 \\
\hline 3 & 30 & & 13 & 14 & 7 \\
\hline 4 & & 3 & 2 & 16 & 16 \\
\hline 5 & $\mathbf{3 0}$ & $\mathbf{4}$ & $\mathbf{2 6}$ & $\mathbf{6 0}$ & $\mathbf{5 0}$ \\
\hline Total & $\mathbf{1 7 . 6 4}$ & $\mathbf{2 . 3 5}$ & $\mathbf{1 5 . 2 9}$ & $\mathbf{3 5 . 2 9}$ & $\mathbf{2 9 . 4 1}$ \\
\hline Avg. & & & & & \\
\hline
\end{tabular}

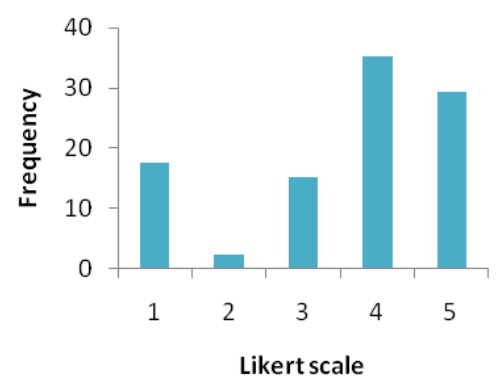

Fig. 7: Graphical representation of Goal 1

\section{Goal: 2}

Need prefect and effective automatic to do select components especially when the large number of components available.

\section{Goal: 2}

Q6: Do you believe there is a level of need for automatic to select component especially when the large number of components available?

Results of total respondents 34 of question 6 given in Table 9 showing that $91 \%$ (where $56 \%$ strongly agreed and $35 \%$ agreed) the people were supportive to question 6 that it is agree that believe there is a high level of need for automatic to select component especially when the large number of components available. The percentage of the people who have a neutral opinion neither agreed nor disagree is $9 \%$. The conclusion of the survey of this question is that believe there is a high level of need for automatic to select component especially when the large number of components available. Following is the Table 9 showing the results obtained for the question 6 .

Table 9: Result for Question 6

\begin{tabular}{|c|c|c|c|}
\hline $\begin{array}{c}\text { Likert } \\
\text { Scale }\end{array}$ & Frequency & Percent & $\begin{array}{c}\text { Cumulative } \\
\text { Percent }\end{array}$ \\
\hline 1 & 0 & $0 \%$ & $0 \%$ \\
\hline 2 & 0 & $0 \%$ & $0 \%$ \\
\hline 3 & 3 & $9 \%$ & $9 \%$ \\
\hline 4 & 12 & $35 \%$ & $44 \%$ \\
\hline 5 & 19 & $56 \%$ & $100 \%$ \\
\hline $\begin{array}{c}\text { Total } \\
\text { respondents }\end{array}$ & $\mathbf{3 4}$ & \multicolumn{2}{|c|}{$\mathbf{1 0 0 \%}$} \\
\hline
\end{tabular}

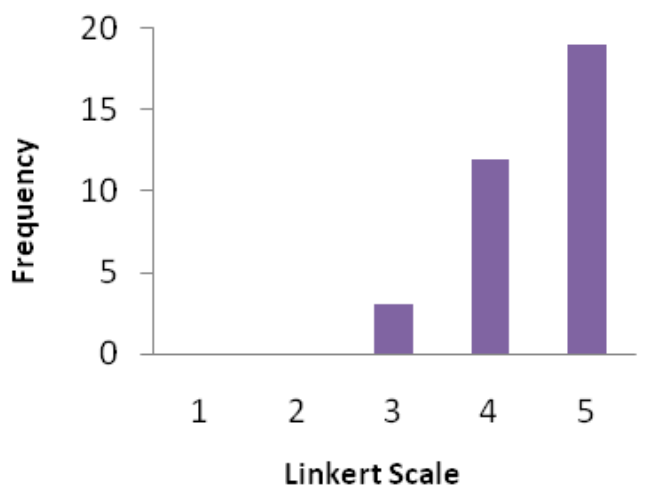

Fig. 8: Graphical Representation of Question 6

Goal: 2

Q7: Do you believe the must used automatic method more effectively to do select components?

Results of total respondents 34 of question 7 given in Table 10 showing that $85 \%$ (where $44 \%$ strongly agreed and $41 \%$ agreed) the people were supportive to question 7 that it is agree that believe the must used automatic method to become more effective to do select components whereas $3 \%$ of the people were not agreed. The percentage of the people who has a neutral opinion neither agreed nor disagree is $12 \%$. The conclusion of the survey of this question is that believe the must used automatic method to become more effective to do select components. Following is the Table 10 showing the results obtained for the question 7 .

Table 10: Result for Question 7

\begin{tabular}{|c|c|c|c|}
\hline $\begin{array}{c}\text { Likert } \\
\text { Scale }\end{array}$ & Frequency & Percent & $\begin{array}{c}\text { Cumulative } \\
\text { Percent }\end{array}$ \\
\hline 1 & 0 & $0 \%$ & $0 \%$ \\
\hline 2 & 1 & $3 \%$ & $3 \%$ \\
\hline 3 & 4 & $12 \%$ & $15 \%$ \\
\hline 4 & 14 & $41 \%$ & $56 \%$ \\
\hline 5 & 15 & $44 \%$ & $100 \%$ \\
\hline $\begin{array}{c}\text { Total } \\
\text { respondents }\end{array}$ & $\mathbf{3 4}$ & \multicolumn{2}{|c|}{$\mathbf{1 0 0 \%}$} \\
\hline
\end{tabular}




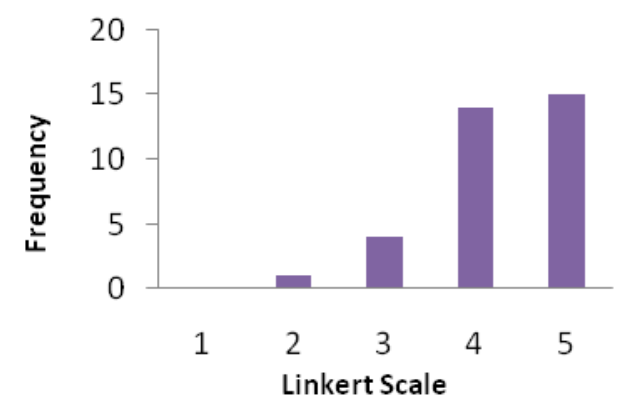

Fig. 9: Graphical Representation of Question 7

\section{Goal: 2}

Q8: How do you rate the possibility of problems when using chooses not perfect automated software for component selection?

Results of total respondents 34 of question 8 given in Table 11 showing that $94 \%$ (where 59\% strongly agreed and $35 \%$ agreed) the people were supportive to question 8 that it is agree that height rate problems when using chooses not perfect automated software for component selection whereas $3 \%$ of the people were not agreed. The percentage of the people who has a neutral opinion neither agreed nor disagree is $3 \%$. The conclusion of the survey of this question is that height rate problem when using chooses not perfect automated software for component selection. Following is the Table 11 showing the results obtained for the question 8 .
Table 11: Result for Question 8

\begin{tabular}{|c|c|c|c|}
\hline $\begin{array}{c}\text { Likert } \\
\text { Scale }\end{array}$ & Frequency & Percent & $\begin{array}{c}\text { Cumulative } \\
\text { Percent }\end{array}$ \\
\hline 1 & 0 & $0 \%$ & $0 \%$ \\
\hline 2 & 1 & $3 \%$ & $3 \%$ \\
\hline 3 & 1 & $3 \%$ & $6 \%$ \\
\hline 4 & 12 & $35 \%$ & $41 \%$ \\
\hline 5 & 20 & $59 \%$ & $100 \%$ \\
\hline $\begin{array}{c}\text { Total } \\
\text { respondents }\end{array}$ & $\mathbf{3 4}$ & \multicolumn{2}{|c|}{$\mathbf{1 0 0 \%}$} \\
\hline
\end{tabular}

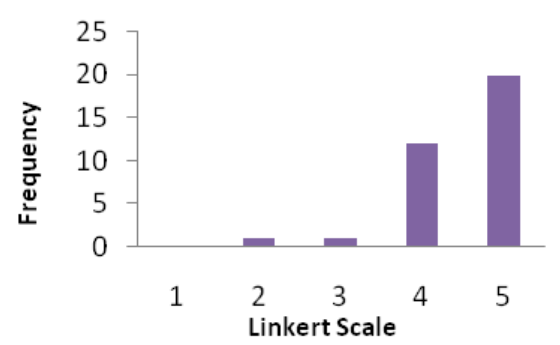

Fig. 10: Graphical Representation of Question 8

\subsection{Cumulative Survey of Goal 2}

In the second goal define need prefect and effective automatic to do select components especially when the large number of components available. That's show $1.96 \%$ are disagree $7.84 \%$ are neither agreed nor disagree $37.25 \%$ are agreed and $52.94 \%$ are strongly agreed.

Table 12: Frequency Table of Cumulative Goal 2

\begin{tabular}{|c|c|c|c|c|c|}
\hline Q.No & Strongly Disagree & Disagree & Neither Agree nor Disagree & Agree & Strongly Agree \\
\hline 6 & & & 3 & 12 & 19 \\
\hline 7 & & 1 & 4 & 14 & 15 \\
\hline 8 & & 1 & 1 & 12 & 20 \\
\hline Total & & $\mathbf{2}$ & $\mathbf{8}$ & $\mathbf{3 8}$ & $\mathbf{5 4}$ \\
\hline Avg. & & $\mathbf{1 . 9 6}$ & $\mathbf{7 . 8 4}$ & $\mathbf{3 7 . 2 5}$ & $\mathbf{5 2 . 9 4}$ \\
\hline
\end{tabular}

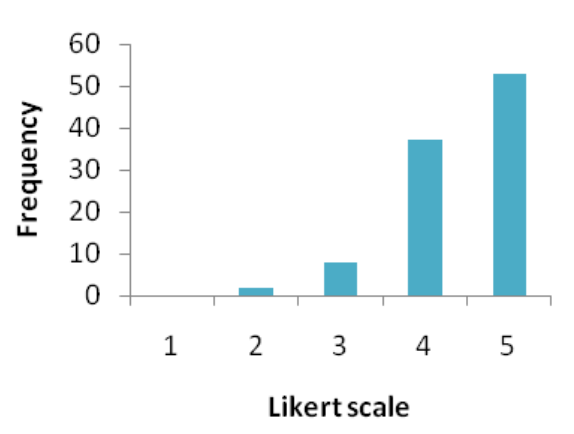

Fig. 11: Graphical representation of Goal 2

\section{Goal: 3}

The prove used improve CBR system to do select the suitable component.
Goal: 3

Q9: How much using improve Case Based Reasoning system for the software component selection problem is acceptable to you as compared with other methods?

Results of total respondents 34 of question 9 given in Table 13 showing that $88 \%$ (where $47 \%$ strongly agreed and $41 \%$ agreed) the people were supportive to question 9 that it is agree improve Case Based Reasoning system for the software component selection problem is acceptable to user as compared with other methods whereas $3 \%$ of the people were not agreed .The percentage of the people who have a neutral opinion neither agreed nor disagree is $9 \%$. The conclusion of the survey of this question is that improve Case Based Reasoning system for the software component selection problem is acceptable to user as 
compared with other methods. Following is the Table 13 showing the results obtained for the question 9.

Table 13: Result for Question 9

\begin{tabular}{|c|c|c|c|}
\hline $\begin{array}{c}\text { Likert } \\
\text { Scale }\end{array}$ & Frequency & Percent & $\begin{array}{c}\text { Cumulative } \\
\text { Percent }\end{array}$ \\
\hline 1 & 0 & $0 \%$ & $0 \%$ \\
\hline 2 & 1 & $3 \%$ & $3 \%$ \\
\hline 3 & 3 & $9 \%$ & $12 \%$ \\
\hline 4 & 14 & $41 \%$ & $53 \%$ \\
\hline 5 & 16 & $47 \%$ & $100 \%$ \\
\hline Total & $\mathbf{3 4}$ & \multicolumn{3}{|c|}{$\mathbf{1 0 0 \%}$} \\
\hline
\end{tabular}

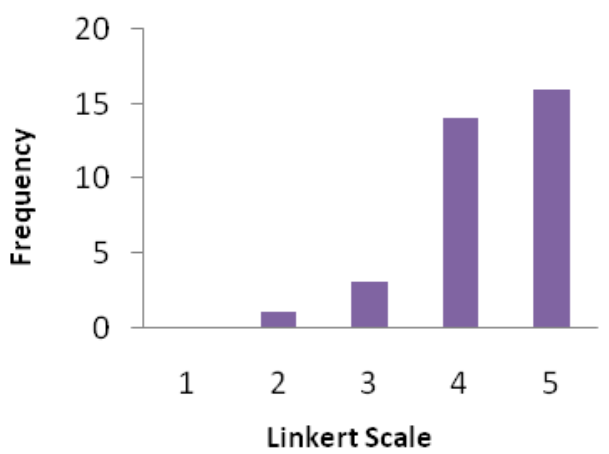

Fig. 12: Graphical Representation of Question 9

\section{Goal: 3}

Q10: Do you believe selected component using the improve CBR system is best to choose for your company?

Results of total respondents 34 of question 10 given in Table 14 showing that $82 \%$ (where $38 \%$ strongly agreed and $44 \%$ agreed) the people were supportive to question 10 that it is agree believe selected component using the improve CBR system is best to choose for their company whereas $3 \%$ of the people were not agreed. The percentage of the people who has a neutral opinion neither agreed nor disagree is $15 \%$. The conclusion of the survey of this question is that believe selected component using the improve CBR system is best to choose for company. Following is the Table 14s howing the results obtained for the question 10 .

Table 14: Result for Question 10

\begin{tabular}{|c|c|c|c|}
\hline $\begin{array}{c}\text { Likert } \\
\text { Scale }\end{array}$ & Frequency & Percent & $\begin{array}{c}\text { Cumulative } \\
\text { Percent }\end{array}$ \\
\hline 1 & 0 & $0 \%$ & $0 \%$ \\
\hline 2 & 1 & $3 \%$ & $3 \%$ \\
\hline 3 & 5 & $15 \%$ & $18 \%$ \\
\hline 4 & 15 & $44 \%$ & $62 \%$ \\
\hline 5 & 13 & $38 \%$ & $100 \%$ \\
\hline Total & $\mathbf{3 4}$ & \multicolumn{2}{|c|}{$\mathbf{1 0 0 \%}$} \\
\hline
\end{tabular}

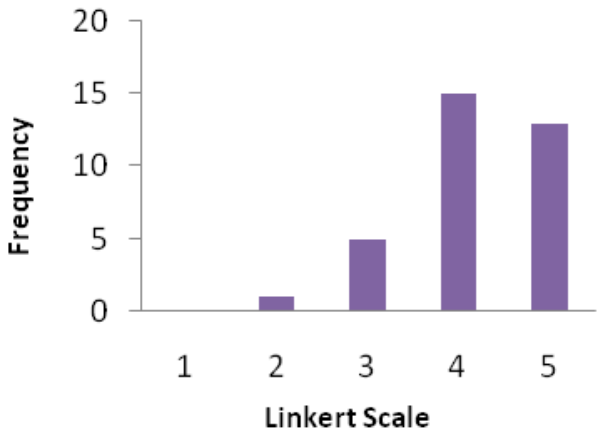

Fig. 13: Graphical Representation of Question 10

\section{Goal: 3}

Q11: Do you find the tasks that using in improving CBR system method is enough to select the suitable component?

Results of total respondents 34 of question 11 given in Table 15 showing that $88 \%$ (where $47 \%$ strongly agreed and $41 \%$ agreed) the people were supportive to question 11 that it is finding the tasks that using in improve CBR system method is enough to select the suitable component whereas $3 \%$ of the people were not agreed. The percentage of the people who have a neutral opinion neither agreed nor disagree is $9 \%$. The conclusion of the survey of this question is that find the tasks that using in improving CBR system method is enough to select the suitable component. Following is the Table 15showing the results obtained for the question 11.

Table 15: Result for Question 11

\begin{tabular}{|c|c|c|c|}
\hline $\begin{array}{c}\text { Likert } \\
\text { Scale }\end{array}$ & Frequency & Percent & $\begin{array}{c}\text { Cumulative } \\
\text { Percent }\end{array}$ \\
\hline 1 & 0 & $0 \%$ & $0 \%$ \\
\hline 2 & 1 & $3 \%$ & $3 \%$ \\
\hline 3 & 3 & $9 \%$ & $12 \%$ \\
\hline 4 & 14 & $41 \%$ & $53 \%$ \\
\hline 5 & 16 & $47 \%$ & $100 \%$ \\
\hline Total & $\mathbf{3 4}$ & \multicolumn{2}{|c|}{$\mathbf{1 0 0 \%}$} \\
\hline
\end{tabular}

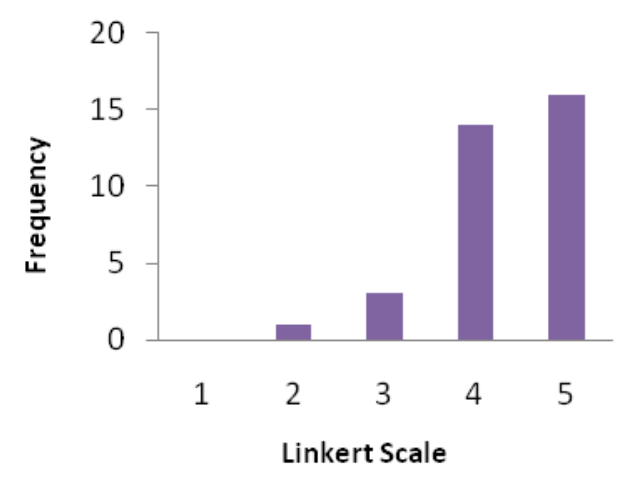

Fig. 14: Graphical Representation of Question 11 


\section{Goal: 3}

Q12: Do you find people work in the company will be satisfied with the use improve the CBR system to select component?

Results of total respondents 34 of question 12 given in Table 16 showing that $82 \%$ (where $38 \%$ strongly agreed and $44 \%$ agreed) the people were supportive to question 12 that it is agree the people work in company will be satisfied with the use improve CBR system to select component whereas $3 \%$ of the people were not agreed. The percentage of the people who has a neutral opinion neither agreed nor disagree is $15 \%$. The conclusion of the survey of this question is that people work in the company will be satisfied with the use improve the CBR system to select component. Following is the Table 16 showing the results obtained for the question 12 .

Table 16: Result for Question 12

\begin{tabular}{|c|c|c|c|}
\hline $\begin{array}{c}\text { Likert } \\
\text { Scale }\end{array}$ & Frequency & Percent & $\begin{array}{c}\text { Cumulative } \\
\text { Percent }\end{array}$ \\
\hline 1 & 0 & $0 \%$ & $0 \%$ \\
\hline 2 & 1 & $3 \%$ & $3 \%$ \\
\hline 3 & 5 & $15 \%$ & $18 \%$ \\
\hline 4 & 15 & $44 \%$ & $62 \%$ \\
\hline 5 & 13 & $38 \%$ & $100 \%$ \\
\hline Total & $\mathbf{3 4}$ & \multicolumn{3}{|c|}{$\mathbf{1 0 0 \%}$} \\
\hline
\end{tabular}

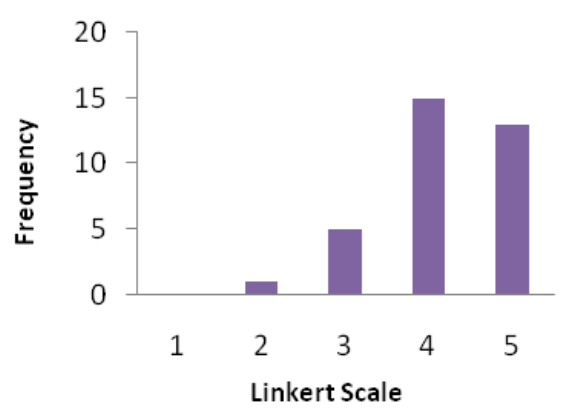

Fig. 15: Graphical Representation of Question 12

Goal: 3

Q13: Do you believe the improve CBR system solution will improve the component selection problem?

Results of total respondents 34 of question 13 given in Table 17 showing that $94 \%$ (where $59 \%$ strongly agreed and $35 \%$ agreed) the people were supportive to question 12 that it is agreed that believe the improve CBR system solution will improve of the component selection problem whereas $3 \%$ of the people were not agreed. The percentage of the people who has a neutral opinion neither agreed nor disagree is 3\%. The conclusion of the survey of this question is that believe the improve CBR system solution will improve the component selection problem. Following is the Table 17 showing the results obtained for the question 13 .
Table 17: Result for Question 13

\begin{tabular}{|c|c|c|c|}
\hline $\begin{array}{c}\text { Likert } \\
\text { Scale }\end{array}$ & Frequency & Percent & $\begin{array}{c}\text { Cumulative } \\
\text { Percent }\end{array}$ \\
\hline 1 & 0 & $0 \%$ & $0 \%$ \\
\hline 2 & 1 & $3 \%$ & $3 \%$ \\
\hline 3 & 1 & $3 \%$ & $6 \%$ \\
\hline 4 & 12 & $35 \%$ & $41 \%$ \\
\hline 5 & 20 & $59 \%$ & $100 \%$ \\
\hline Total & 34 & \multicolumn{2}{|c|}{$\mathbf{1 0 0 \%}$} \\
\hline
\end{tabular}

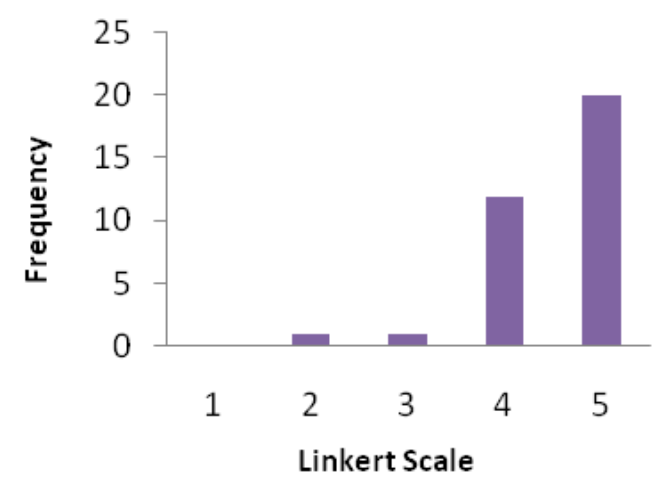

Fig. 16: Graphical Representation of Question 13

Goal: 3

Q14: Do you agree that the improve CBR system does not really give satisfied result?

Results of total respondents 34 of question 14 given in Table 18 showing that $94 \%$ (where $38 \%$ s strongly disagree and $56 \%$ disagree) the people were not supportive question 14 that it is not agreed that the improve CBR system does not really give satisfying results whereas $3 \%$ of the people were agreed. The percentage of the people who has a neutral opinion neither agreed nor disagree is $3 \%$. The conclusion of the survey of this question is that not agree that the improve CBR system does not really give satisfied result. Following is the Table 18 showing the results obtained for the question 14 .

Table 18: Result for Question 14

\begin{tabular}{|c|c|c|c|}
\hline $\begin{array}{c}\text { Likert } \\
\text { Scale }\end{array}$ & Frequency & Percent & $\begin{array}{c}\text { Cumulative } \\
\text { Percent }\end{array}$ \\
\hline 1 & 13 & $38 \%$ & $38 \%$ \\
\hline 2 & 19 & $56 \%$ & $94 \%$ \\
\hline 3 & 1 & $3 \%$ & $97 \%$ \\
\hline 4 & 1 & $3 \%$ & $100 \%$ \\
\hline 5 & 0 & $0 \%$ & $100 \%$ \\
\hline Total & $\mathbf{3 4}$ & \multicolumn{2}{|c|}{$\mathbf{1 0 0 \%}$} \\
\hline
\end{tabular}




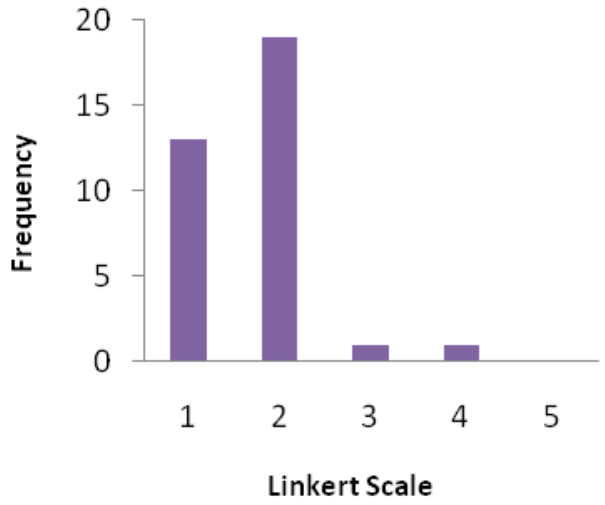

Fig. 17: Graphical Representation of Question 14

\section{Goal: 3}

Q15: Do you recommend an improved CBR system for the component selection problem to be used in your company?

Results of total respondents 34 of question 15 given in Table 19 showing that $85 \%$ (where $38 \%$ strongly agreed and $47 \%$ agree) the people were supportive to question 15 that it is agree recommend a improve CBR system for the component selection problem to be used in company whereas $3 \%$ of the people were not agreed. The percentage of the people who has a neutral opinion neither agreed nor disagree is $12 \%$. The conclusion of the survey of this question is that recommend a improve CBR system for the component selection problem to be used in company. Following is the Table 19 showing the results obtained for the question 15 .
Table 19: Result for Question 15

\begin{tabular}{|c|c|c|c|}
\hline $\begin{array}{c}\text { Likert } \\
\text { Scale }\end{array}$ & Frequency & Percent & $\begin{array}{c}\text { Cumulative } \\
\text { Percent }\end{array}$ \\
\hline 1 & 0 & $0 \%$ & $0 \%$ \\
\hline 2 & 1 & $3 \%$ & $3 \%$ \\
\hline 3 & 4 & $12 \%$ & $15 \%$ \\
\hline 4 & 16 & $47 \%$ & $62 \%$ \\
\hline 5 & 13 & $38 \%$ & $100 \%$ \\
\hline Total & $\mathbf{3 4}$ & \multicolumn{2}{|c|}{$\mathbf{1 0 0 \%}$} \\
\hline
\end{tabular}

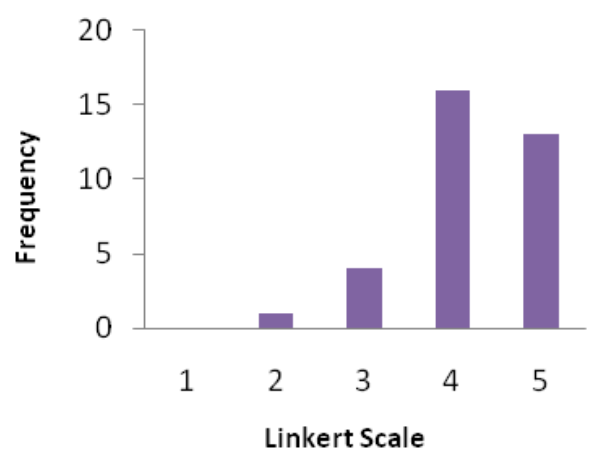

Fig. 18: Graphical Representation of Question 15

\subsection{Cumulative Survey of Goal 3}

In the last goal the prove used improve CBR system to do select the suitable component. That's show $5.46 \%$ are strongly disagreed $10.50 \%$ are disagree $9.24 \%$ are neither agreed nor disagree $36.55 \%$ are agreed and $38.23 \%$ are strongly agreed.

Table 20: Frequency Table of Cumulative Goal 3

\begin{tabular}{|c|c|c|c|c|c|}
\hline Q.No & Strongly Disagree & Disagree & Neither Agree nor Disagree & Agree & Strongly Agree \\
\hline 9 & & 1 & 3 & 14 & 16 \\
\hline 10 & & 1 & 5 & 15 & 13 \\
\hline 11 & & 1 & 3 & 14 & 16 \\
\hline 12 & & 1 & 5 & 15 & 13 \\
\hline 13 & & 1 & 1 & 12 & 20 \\
\hline 14 & 13 & 19 & 1 & 1 & \\
\hline 15 & & 1 & 4 & 16 & 13 \\
\hline Total & 13 & 25 & 22 & 87 & 91 \\
\hline Avg. & 5.46 & 10.50 & 9.24 & 36.55 & 38.23 \\
\hline
\end{tabular}

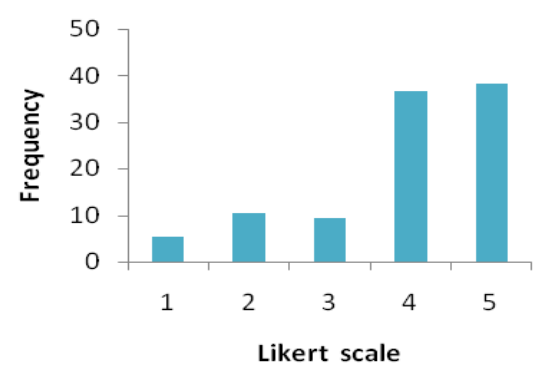

\subsection{Cumulative Evaluation of 3 Goals}

In the last section the evaluation of 3 Goals that's showing the result $8.43 \%$ are strongly disagreed $6.07 \%$ are disagree $10.98 \%$ are neither agreed nor disagree $36.27 \%$ are agreed and $38.23 \%$ are strongly agreed.

Fig. 19: Graphical representation of Goal 3 
Table 21: Frequency Table of Cumulative 3 Goals

\begin{tabular}{|c|c|c|c|c|c|}
\hline Q.No & Strongly Disagree & Disagree & Neither Agree nor Disagree & Agree & Strongly Agree \\
\hline 1 & & 1 & 7 & 11 & 15 \\
\hline 2 & & & 3 & 19 & 12 \\
\hline 3 & & & 13 & 14 & 7 \\
\hline 4 & 30 & 3 & 1 & & \\
\hline 5 & & & 2 & 16 & 16 \\
\hline 6 & & & 3 & 12 & 19 \\
\hline 7 & & 1 & 4 & 14 & 15 \\
\hline 8 & & 1 & 1 & 12 & 2 \\
\hline 9 & & 1 & 3 & 14 & 16 \\
\hline 10 & & 1 & 5 & 15 & 13 \\
\hline 11 & & 1 & 3 & 14 & 16 \\
\hline 12 & & 1 & 5 & 15 & 13 \\
\hline 13 & & 1 & 1 & 12 & 20 \\
\hline 14 & 13 & 19 & 1 & 1 & \\
\hline 15 & & 1 & 4 & 16 & 13 \\
\hline Total & 43 & 31 & 56 & 185 & 195 \\
\hline Avg. & 8.43 & 6.07 & 10.98 & 36.27 & 38.23 \\
\hline
\end{tabular}

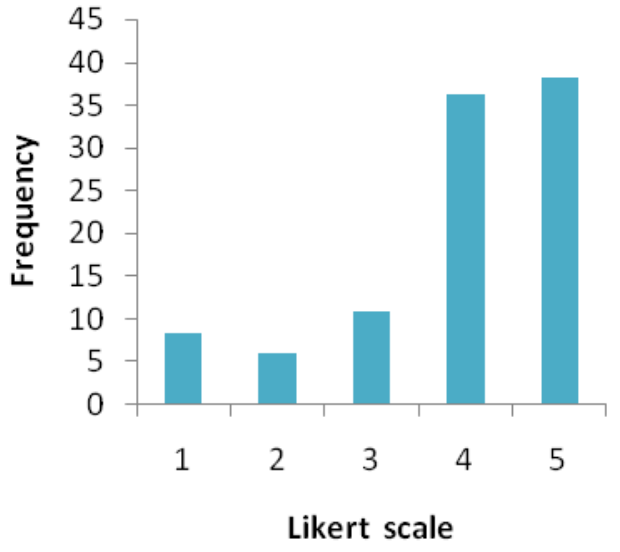

Fig. 20: Graphical representation of Cumulative 3 Goals

\section{Conclusion and Future Work}

The authors proposed a solution for one of the basic difficulties connecting with the component reuse. This solution tackles how to identify appropriate components to satisfy users' requirements. The seriousness of this problem increases with the emersion of the Component Based Software Engineering. The results of survey reflect that the proposed solution improves the situation of 'Case Based Reasoning System' to select a suitable component as it is deemed by the respondents of questionnaire.

The future work, of this paper, is to conduct further research to tackle the various usages of the past decisions in order to enhance the future decisions that will be taken relying on improve Case Based Reasoning System.

\section{References}

[1] Haghpanah N, Moaven S, et al. Approximation Algorithms for Software Component Selection Problem [C]. In: 14th Asia-Pacific Software Engineering Conference,2007,159-166.

[2] Vescan A, Grosan C. Evolutionary Algorithms for the Component Selection Problem[C].In: Database and Expert Systems Application, 2008,19: 509-513.

[3] Vescan A, Grosan C, et al. Two Evolutionary Multiobjective Approaches for the Component Selection Problem[C].In: Intelligent Systems Design and Applications, Nov. 2008,2: 395-400.

[4] Vescan A. A Metrics-Based Evolutionary Approach for the Component Selection Problem[C].In: Computer Modelling and Simulation, 2009. 11: 83-88.

[5] Vescan A. Pareto Dominance-Based Approach for the Component Selection Problem[C]. In:Computer Modeling and Simulation, 2008,2: 58-63.

[6] Vescan A. An evolutionary multiobjective approach for the component selection problem[C].In: Applications of Digital Information and Web Technologies(ICADIWT 2008), 1,252257.

[7] Calvert C, Hamza-Lup G, et al. An integrated component selection framework for system-level design[C].In:Systems Conference (SysCon), IEEE International, 2011,261-266.

[8] Kaur A, Mann K. Component Selection for Component based Software Engineering[J]. 
International Journal of Computer Applications, 2010, 2 (1):109-114.

[9] Hamza-Lup G, Agarwal A, et al. Component selection strategies based on system requirements' dependencies on component attributes[C]. In: Systems Conference 2nd Annual IEEE, 2008, 1-5.

[10] Fahmi S, Choi H. A study on software component selection methods [C]. In:Advanced Communication Technology (ICACT 2009) Feb 2009,01:288-292 .

[11] Akashah E, Rizal S, et al. Knowledge Sharing Platform Framework using Case Based Reasoning[C]. In: International Conference on Information and Intelligent Computing, 2011, 18:76-80.

\section{Authors' Profiles}

Abrar Omar Al-khamisi: Graduate Student of Information Technology, Faculty of Computing \& Information Technology, King Abdul-Aziz University, major in Information Technology Management.

M. Rizwan Jameel Qureshi: Assistant Professor of Information Technology, Faculty of Computing \& Information Technology, King Abdul-Aziz University, major in software engineering and database management systems.

How to cite this paper: Abrar Omar Alkhamisi, M. Rizwan Jameel Qureshi,"A Proposal of Case Based Reasoning System for the Appropriate Selection of Components Using CBD", International Journal of Information Technology and Computer Science(IJITCS), vol.5, no.9, pp.43-55, 2013. DOI: 10.5815/ijitcs.2013.09.04 